\title{
Experimental Finite Element Approach for Stress Analysis
}

\author{
Ahmet Erklig and M. Akif Kütük \\ Mechanical Engineering Department, University of Gaziantep, 27310 Gaziantep, Turkey \\ Correspondence should be addressed to Ahmet Erklig; erklig@gantep.edu.tr \\ Received 25 December 2013; Accepted 22 April 2014; Published 11 May 2014 \\ Academic Editor: Jong M. Park \\ Copyright (C) 2014 A. Erklig and M. A. Kütük. This is an open access article distributed under the Creative Commons Attribution \\ License, which permits unrestricted use, distribution, and reproduction in any medium, provided the original work is properly \\ cited. \\ This study aims to determining the strain gauge location points in the problems of stress concentration, and it includes both \\ experimental and numerical results. Strain gauges were proposed to be positioned to corresponding locations on beam and blocks \\ to related node of elements of finite element models. Linear and nonlinear cases were studied. Cantilever beam problem was selected \\ as the linear case to approve the approach and conforming contact problem was selected as the nonlinear case. An identical mesh \\ structure was prepared for the finite element and the experimental models. The finite element analysis was carried out with ANSYS. \\ It was shown that the results of the experimental and the numerical studies were in good agreement.
}

\section{Introduction}

The finite element method is one of the efficient and wellknown numerical methods for various engineering problems. For the last 30 years it has been used for the solution of many types of problems. Finite element results are validated with either analytical solution or experimental studies. Many experimental researches have been carried out in many areas.

Wei and Zhao [1] determined mode-I stress intensity factor with finite element analysis and experimental test. In this experimental study, two strain gauges were used to determine the stress intensity factor. Simandjuntak et al. [2] studied fatigue crack closure of a corner crack. They also compared finite element predictions with experimental results. They used four strain gauges around the crack tips to determine the opening stress levels and compliance curves.

Briscoe and Chateauminois [3] described an experimental study combined with analyses and numerical simulations of the surface strains developed in a metal-polymer contact under a variety of loading configurations. They used four strain gauges which were located near the contact area to determine friction coefficient under torsion and sliding motion.

Kanehara and Fujioka [4] tried to develop a method of measuring rail/wheel lateral contact point by improving conventional method of measuring wheel load and lateral force in which strain of the disk surface was used for measuring these forces. Seven pairs of strain gauges were placed on the surface of the hole to detect compressive strain by wheel load. Four pairs of strain gauges were placed on the surface of the disk to detect surface strain by disk bend. ElAbbasi et al. [5] studied appropriate variational inequalities formulation corresponding to shell contact. Photoelastic and strain gauge measurements were used to validate their new proposed approach. Only one strain gauge was attached to the inner radius of the tested rings to measure the circumferential strain at different angular positions.

Cordey and Gautier [6] studied mechanical testing of bones with the use of strain gauges. They used ship tibia for the analysis and used $45^{\circ}$ strain rosette. Barker et al. [7] tried to validate a finite element model of the human metacarpal. A right index human metacarpal was subjected to torsion and combined axial/bending loading using strain gauge and 3D finite element analysis. Six strain gauges were used in the experiment under static loading. Akça et al. [8] compared three-dimensional finite element (FE) stress analysis with in vitro strain gauge measurements on dental implants. There were differences regarding the quantification of strains between strain gauge analysis and three-dimensional finite element stress analysis. However, there was a mutual agreement and compatibility between three-dimensional finite element stress analysis and in vitro strain gauge analysis on 


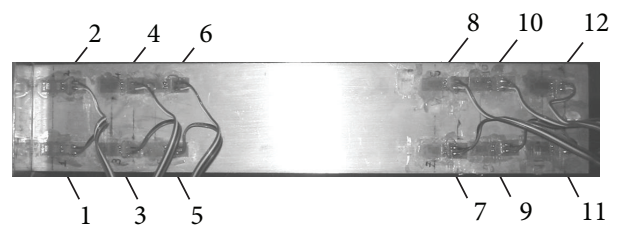

FIGURE 1: Application of strain gauges.
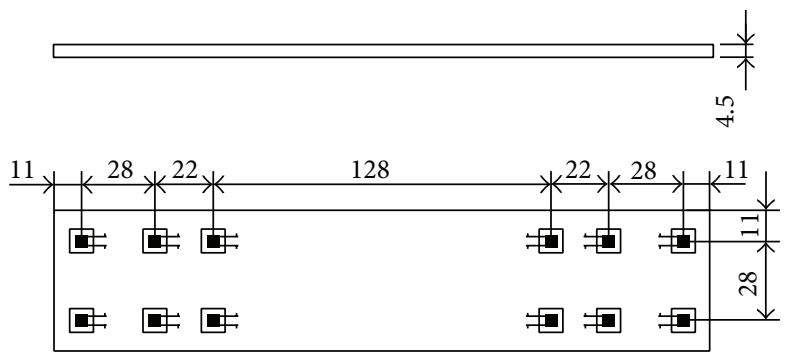

Figure 2: Dimensions of the cantilever beam in millimeters.
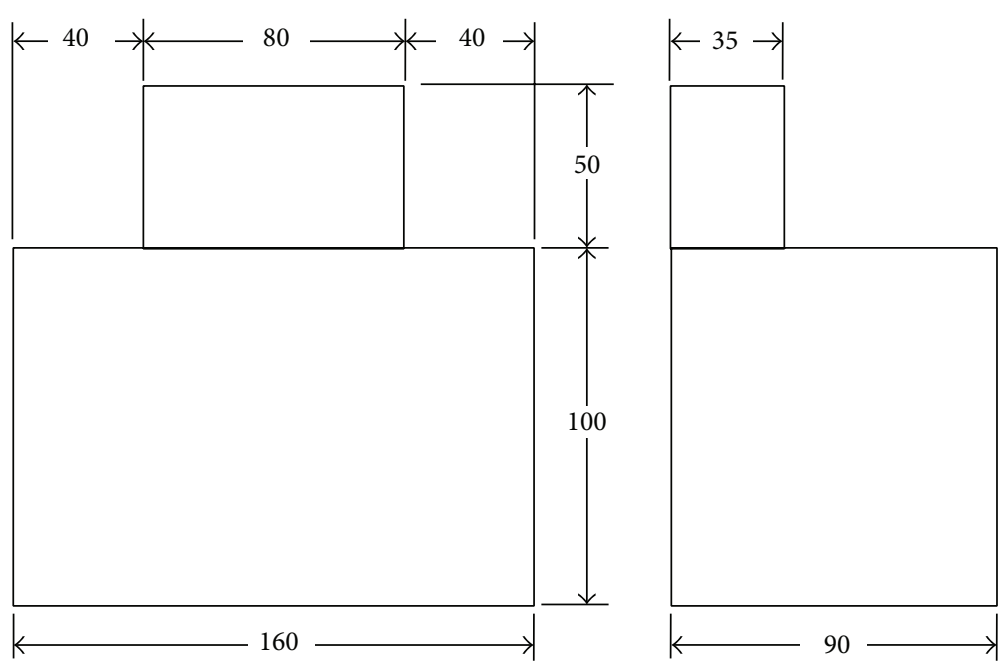

Figure 3: Dimensions of the aluminum blocks in millimeters.
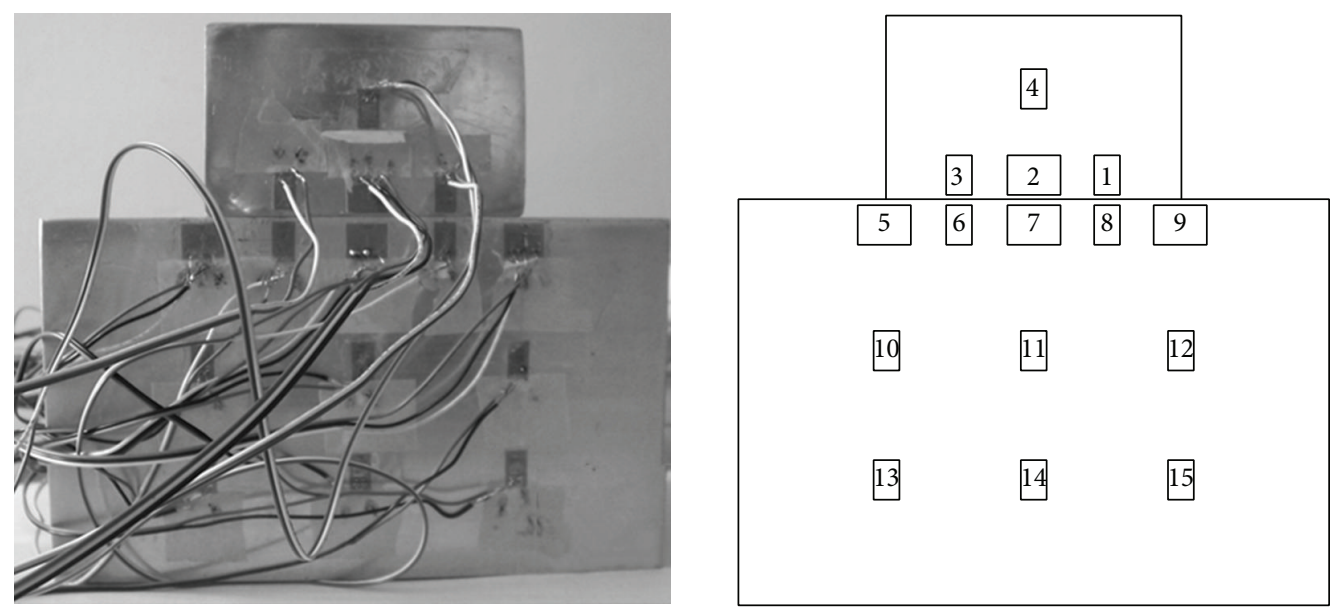

FIGURE 4: Strain gauge applications. 


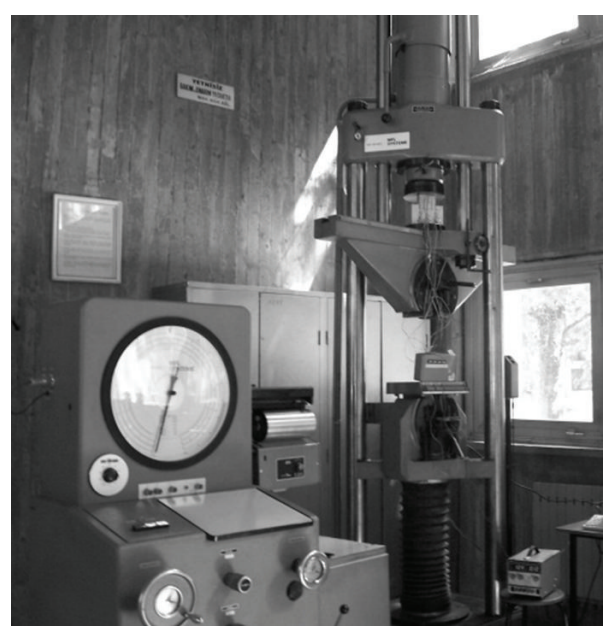

FIGURE 5: 60 tons capacity MFL hydraulic machine.

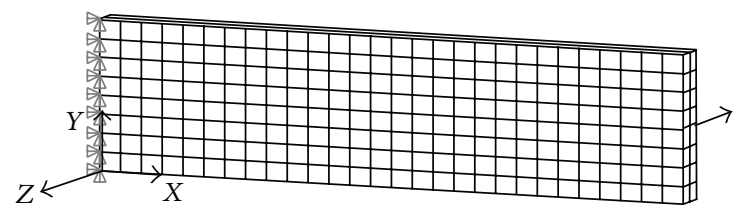

FIGURE 6: Finite element mesh and loading and boundary conditions of the beam.

the determination of the quality of induced strains under applied load. Reymer [9] studied on the validation process of the numerical model of the Mi-24 helicopter tail boom and vertical stabilizer. FE model was validated using strain measurements of the real structure during characteristic flight maneuvers. A system of foil strain gauges was installed on the tail boom in previously selected locations. Detailed analysis of the results confirmed that after some minor modifications the developed FE model represents the actual structure reasonably well. Particular attention was paid to the representation of the boundary conditions and how to implement loads, which can significantly affect the obtained results.

In those studies, strain gauges were placed on highly stressed zones but it was not discussed if the strain gauges were at the ideal position. According to deviation in placement of the gauges there may be a difference between the experimental and the numerical analysis results. In addition, strain gauges have never been used in contact regions. In this paper, an approach is suggested to obtain more accurate results for contact region from comparison of finite element and experimental results. Thus, strain gauge locations on real model are selected as corresponding points at finite element model which are nodes of element. Cantilever beam problem is considered for the linear case to approve the approach. Conforming contact problem is considered for the nonlinear case with stress concentration. An identical mesh structure is prepared for finite element and experimental models. Strain gauges are located at positions on beam and blocks, corresponding to nodes of elements in the finite element models. The results from the experiment are then compared with finite element analysis.

\section{Materials and Experimental Procedure}

An aluminum beam was fixed at one end and point load was applied to the other end for beam problem case. In the conforming contact case, two aluminum blocks were machined with different dimensions. The smaller block was placed on the other block and loading was applied to the top of the upper block.

Strain gauges were centered and bonded to positions on the beam and blocks corresponding to the nodes of the elements of the finite element models. Strain gauge measurements were performed with data logger. Measured output voltages were transferred to the strain value as

$$
\varepsilon=\frac{-4 V_{r}}{\mathrm{GF}\left(1+2 V_{r}\right)}, \quad V_{r}=\frac{\left(V_{\text {out,strained }}-V_{\text {out,unstrained }}\right)}{V_{\text {in }}},
$$

where $V_{\text {out,unstrained }}$ is the initial output voltage, $V_{\text {out,strained }}$ is the voltage resulting from straining the material, $V_{\text {in }}$ is the input/excitation voltage, and GF is the gauge factor.

2.1. Linear Case. This case involves the bending of a rectangular cross-section aluminum beam as shown in Figure 1. Strain gauges were bonded to the beam at nodes of an element. The strain gauges' locations and dimensions of the beam are shown in Figure 2. Material properties obtained from tension test are given in Table 1. 


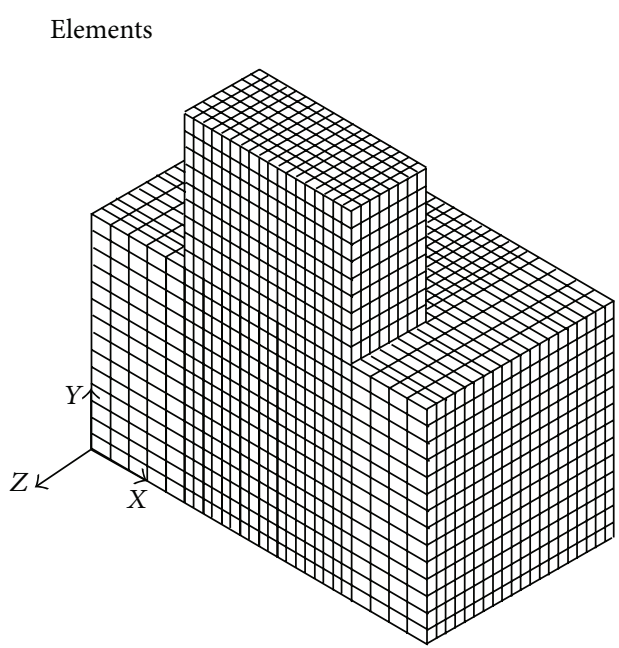

(a) Finite element model

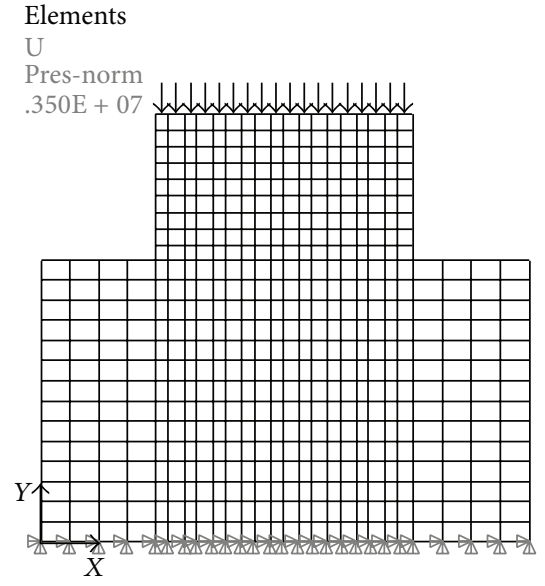

(b) Loading and boundary conditions

FIGURE 7: Finite element model and loading and boundary conditions of blocks.

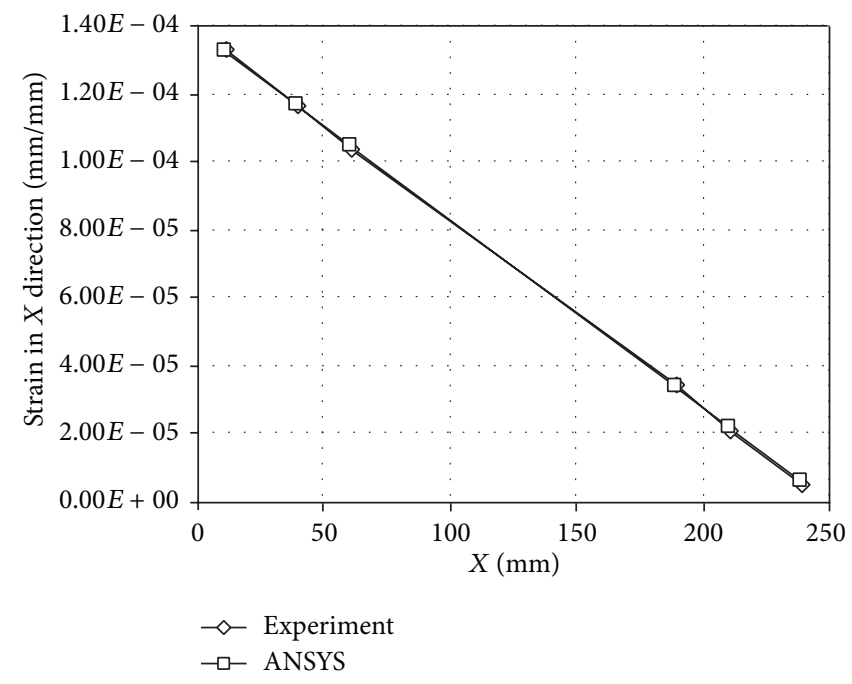

FIgURE 8: $\varepsilon_{x}$ distribution along beam.

TABLE 1: Mechanical properties of the aluminum alloy block.

\begin{tabular}{lccc}
\hline Orientation & $\begin{array}{c}\text { Elastic } \\
\text { modulus } \\
(\mathrm{GPa})\end{array}$ & $\begin{array}{c}\text { Yield stress } \\
(\mathrm{MPa})\end{array}$ & $\begin{array}{c}\text { Ultimate tensile } \\
\text { stress } \\
(\mathrm{MPa})\end{array}$ \\
\hline Longitudinal & 105 & 365 & 436 \\
\hline
\end{tabular}

Load is applied to the beam as a point load at the end of the beam by the increment of $0.5 \mathrm{~kg}$ from 0.5 to $5 \mathrm{~kg}$ and measurements were read from the strain gauge indicator.

2.2. Nonlinear Case. Two aluminum alloy blocks were manufactured to the geometry shown in Figure 3. Material properties of the blocks are the same as that of the beam and are given in Table 1 . The blocks were divided to small areas representing the finite elements. Strain gauges were bonded to several points to determine strain distribution over contact region and all over the block. Two types of strain gauges, four two-way gauges and eleven one-way gauges, were used. Wheatstone bridge was connected to take output voltage from active gauge. Strain gauges were linked to the data logger to read the output voltage. Static load was applied to the upper block as $1,2,3,4,5$, and 6 tons.

After the application of strain gauges as illustrated in Figure 4, the blocks are loaded using a 60-ton MFL hydraulic machine (Figure 5).

\section{Finite Element Models}

Three-dimensional finite element analysis was performed. The strain values were determined at nodal points of corresponding finite element. 


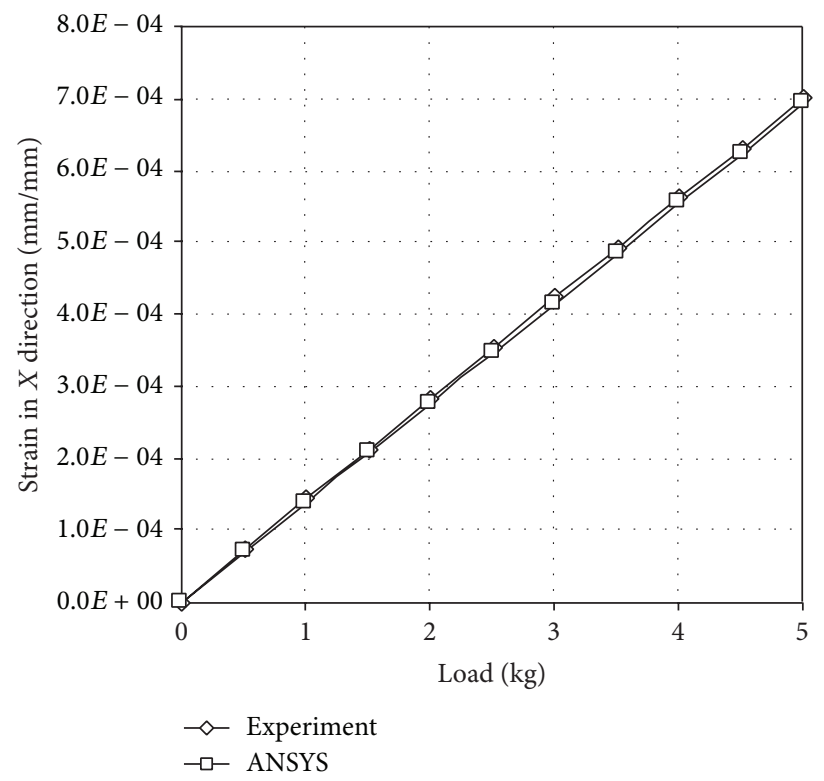

FIGURE 9: $\varepsilon_{x}$ distribution of gauges 1 and 2 under static loading.

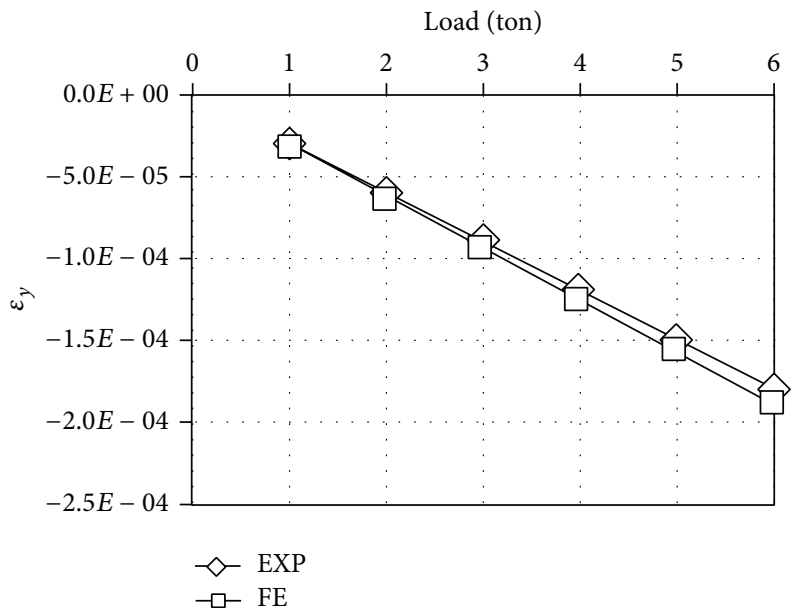

(a) Gauge 7

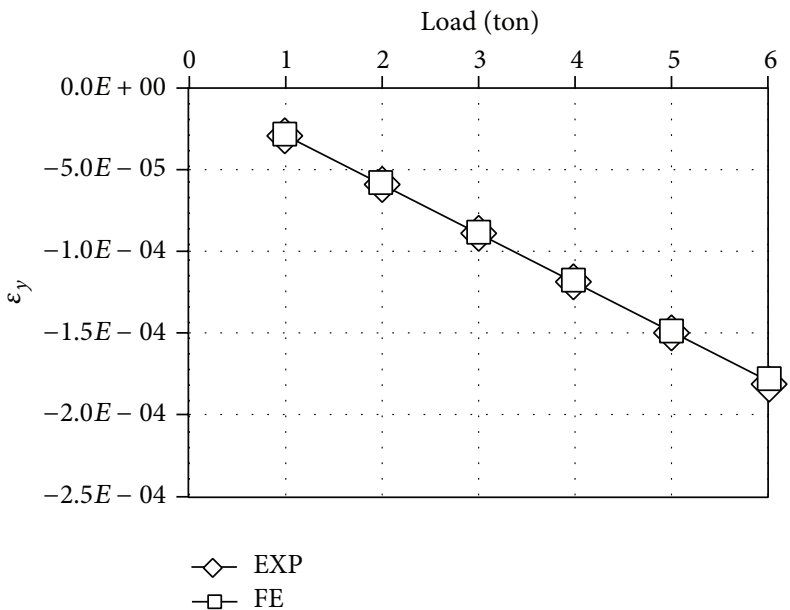

(b) Gauge 11

FIGURE 10: $\varepsilon_{y}$ distribution of noncontacted gauges 11 and 12 .

3.1. FE Analysis of Linear Case. The beam was modeled with the finite element software ANSYS. SOLID186 [10] element was used. The mesh is shown in Figure 6. The material is modeled as linear, elastic, and isotropic.

3.2. FE Analysis of Nonlinear Case. A model of the contacting blocks was developed using ANSYS. A small grid size was used to get acceptable finite element result. The mesh, as illustrated in Figure 7, consists of three-dimensional SOLID45 [10] type elements and TARGE170 [10] and CONTAC174 [10] contact elements in contact region. Boundary conditions and loading are shown in Figure 7. The material properties are given in Table 1 . Friction coefficient, $\mu=0.1$, is used between two blocks. Elastic contact analysis was carried on. Six different static loads were applied to the upper block as
$1,2,3,4,5$, and 6 tons. The finite element analysis gives the strain of each node in the bonded strain gauge points.

\section{Results}

Strain variation along $x$-axis of the cantilever beam is shown in Figure 8. Strain variation for gauges 1 and 2 under different loadings is illustrated in Figure 9.

Almost the same values of strain are observed for the experimental and the numerical cases. For this linear case with stress concentration free condition, stress varies smoothly and linearly. Hence the deviation of strain gauge position will not affect the results significantly.

In the nonlinear case, strain is changed in $y$ direction of gauges 11 and 12 under different loading values as shown in 


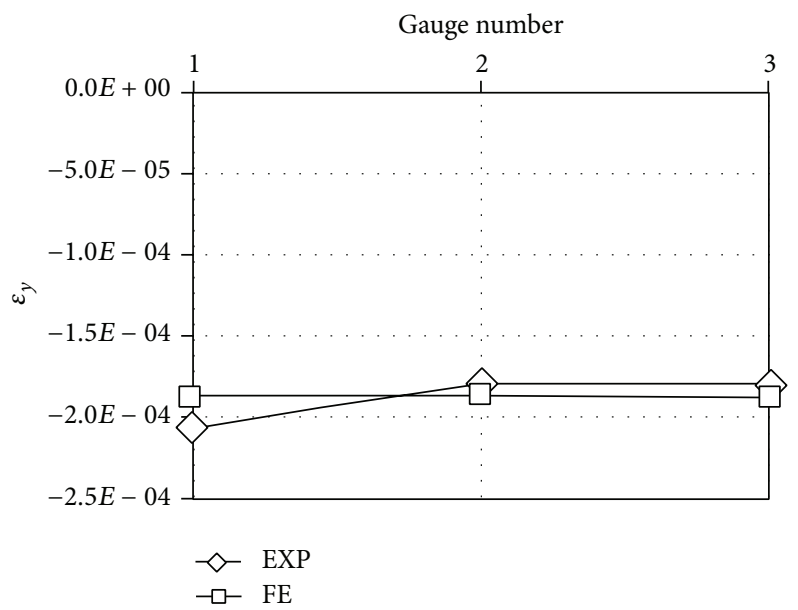

(a) Upper block

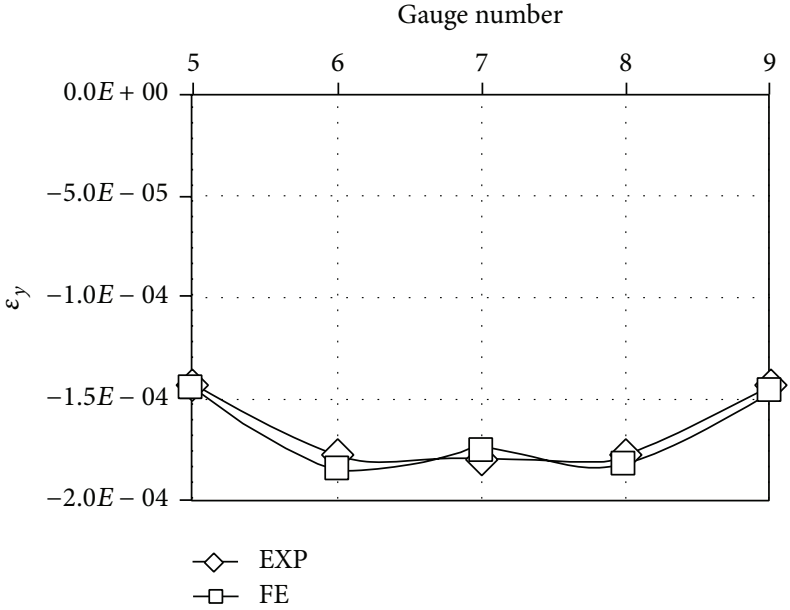

(b) Lower block

FIGURE 11: $\varepsilon_{y}$ distribution of contact line for 6 tones.

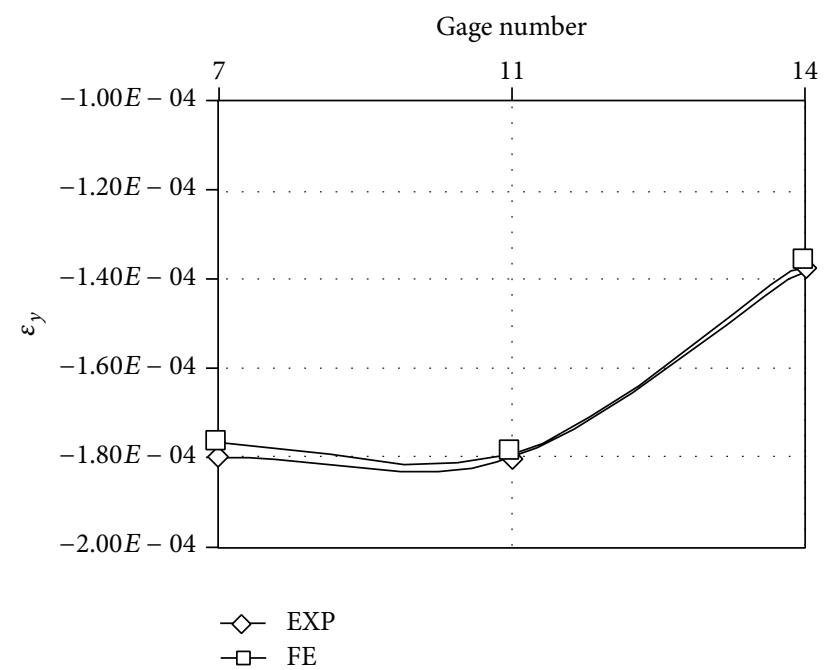

FIGURE 12: $\varepsilon_{y}$ distribution of lower block for 6 tones.

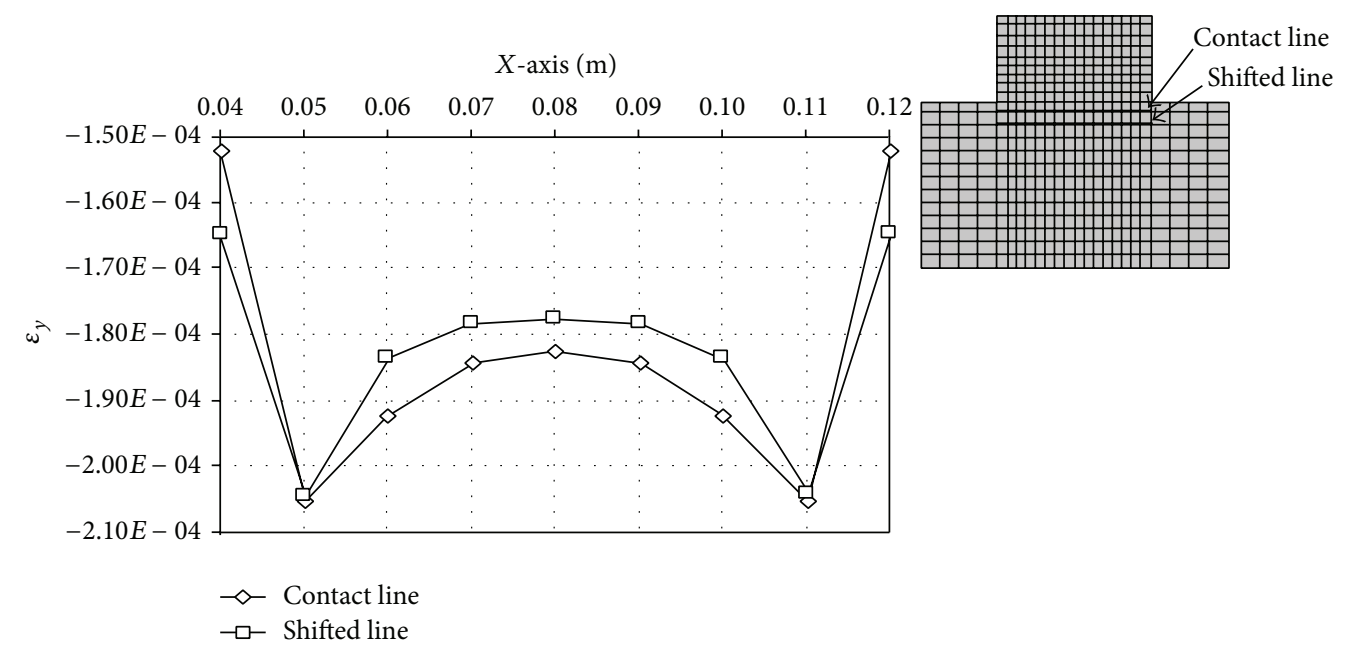

FIGURE 13: Comparison of $\varepsilon_{y}$ for real and shifted contact lines. 
Figure 10. Comparison of the reading for strain in $y$ direction and finite element results in upper and bottom block contact line for 6 tons is shown in Figure 11. Variation of strain in $y$ direction is plotted in Figure 12.

The case study for conforming contact also includes stress concentrations at the locations where the peripheral of small block contacts with the larger one. The attention is concentrated to these locations: sudden stress variation is observed at these concentration points. Hence, the use of strain gauges at incorrect locations will yield some errors. The amount of possible error with small deviations of location is searched in Figure 13. In this figure, the amount of deviation between strain values with dislocation is observed to be up to $10 \%$. During the experimental studies, the exact location of strain gauges and numerical analysis check points need attention due to rapid change of stress value with location.

\section{Conclusion}

The suggested approach gives a better comparison with the results of finite elements and experimental studies. While the linear case results are identical due to linearity of the problem; the accuracy of nonlinear case results is very high. For the nonlinear case and existence of stress concentration, strain measurement and placement of strain gauges require more attention due to rapid change of the stress value. Any dislocation of strain gauge is shown to yield an error of up to $10 \%$.

\section{Conflict of Interests}

The authors declare that there is no conflict of interests regarding the publication of this paper.

\section{References}

[1] J. Wei and J. H. Zhao, "A two-strain-gage technique for determining mode I stress-intensity factor," Theoretical and Applied Fracture Mechanics, vol. 28, pp. 135-140, 1997.

[2] S. Simandjuntak, H. Alizadeh, M. J. Pavier, and D. J. Smith, "Fatigue crack closure of a corner crack: a comparison of experimental results with finite element predictions," International Journal of Fatigue, vol. 27, no. 8, pp. 914-919, 2005.

[3] B. J. Briscoe and A. Chateauminois, "Measurements of frictioninduced surface strains in a steel/polymer contact," Tribology International, vol. 35, no. 4, pp. 245-254, 2002.

[4] H. Kanehara and T. Fujioka, "Measuring rail/wheel contact points of running railway vehicles," Wear, vol. 253, no. 1-2, pp. 275-283, 2002.

[5] N. El-Abbasi, J. S. Cirne, and S. A. Meguid, "Numerical and experimental investigations of contact in thin and thick rings," International Journal of Mechanical Sciences, vol. 41, no. 9, pp. 1051-1066, 1999.

[6] J. Cordey and E. Gautier, "Strain gauges used in the mechanical testing of bones. Part II: "in vitro" and "in vivo" technique," Injury, vol. 30, no. 1, pp. S-A14-S-A20, 1999.

[7] D. S. Barker, D. J. Netherway, J. Krishnan, and T. C. Hearn, "Validation of a finite element model of the human metacarpal," Medical Engineering \& Physics, vol. 27, no. 2, pp. 103-113, 2005.
[8] K. Akça, M. C. Çehreli, and H. İplikçioğlu, "A comparison of three dimensional finite element stress analysis with in vitro strain gauge measurements on dental implants," The International Journal of Prosthodontics, vol. 15, no. 2, pp. 115-121, 2002.

[9] P. Reymer, "Validation of the fem model of the mi-24 tail boom and vertical stabilizer," Journal of KONES Powertrain and Transport, vol. 18, no. 2, pp. 369-376, 2011.

[10] ANSYS Procedures, Engineering Analysis System Verification Manual, vol. 1, Swanson Analysis System, Houston, Pa, USA, 1993. 

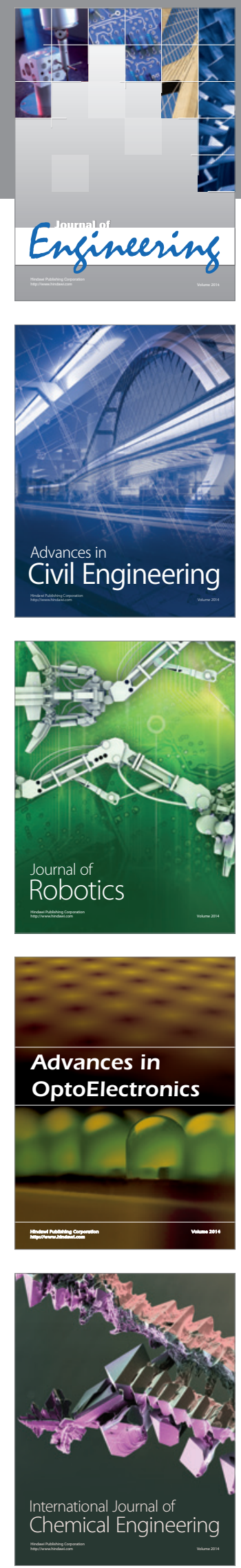

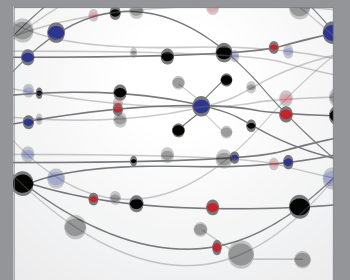

The Scientific World Journal
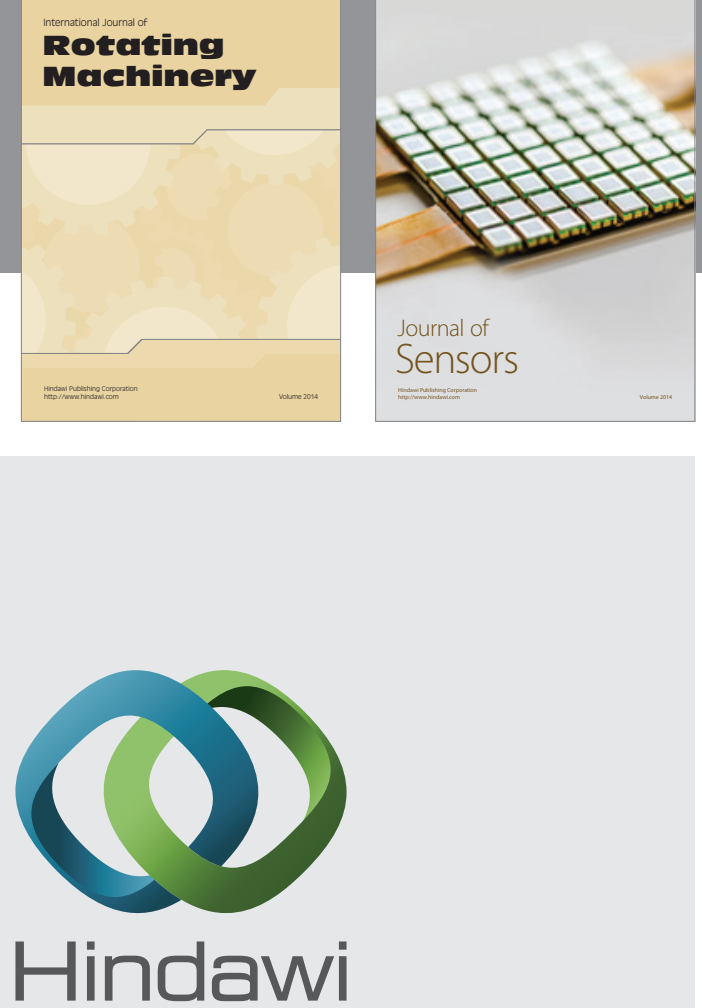

Submit your manuscripts at http://www.hindawi.com
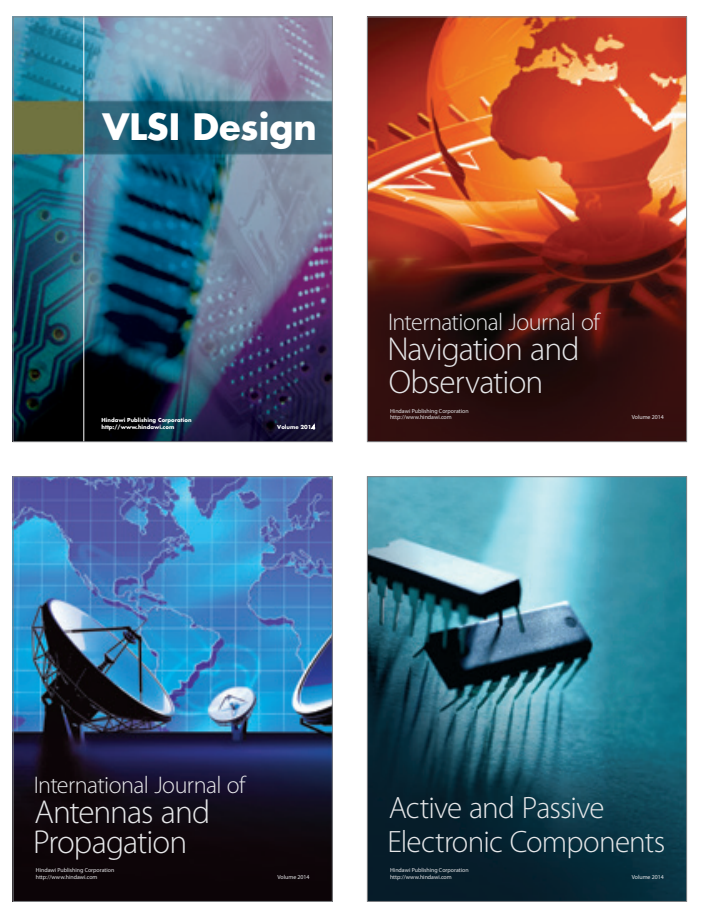
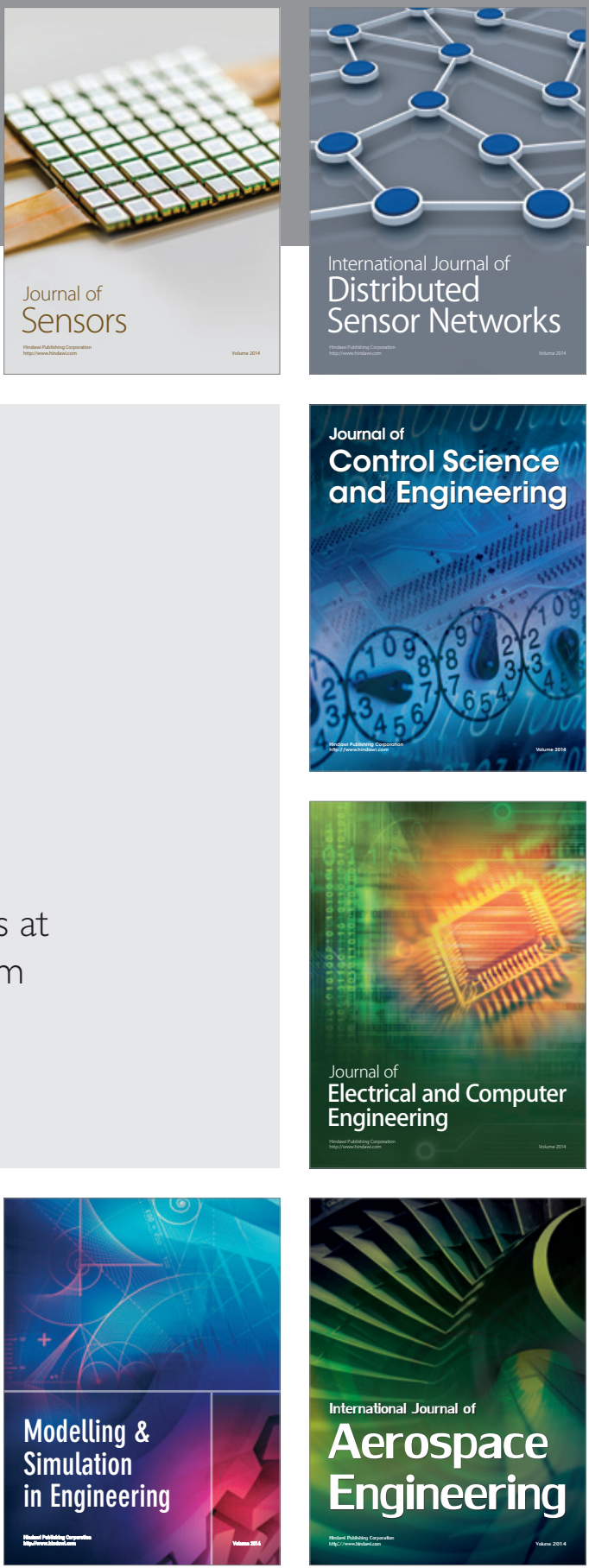

Journal of

Control Science

and Engineering
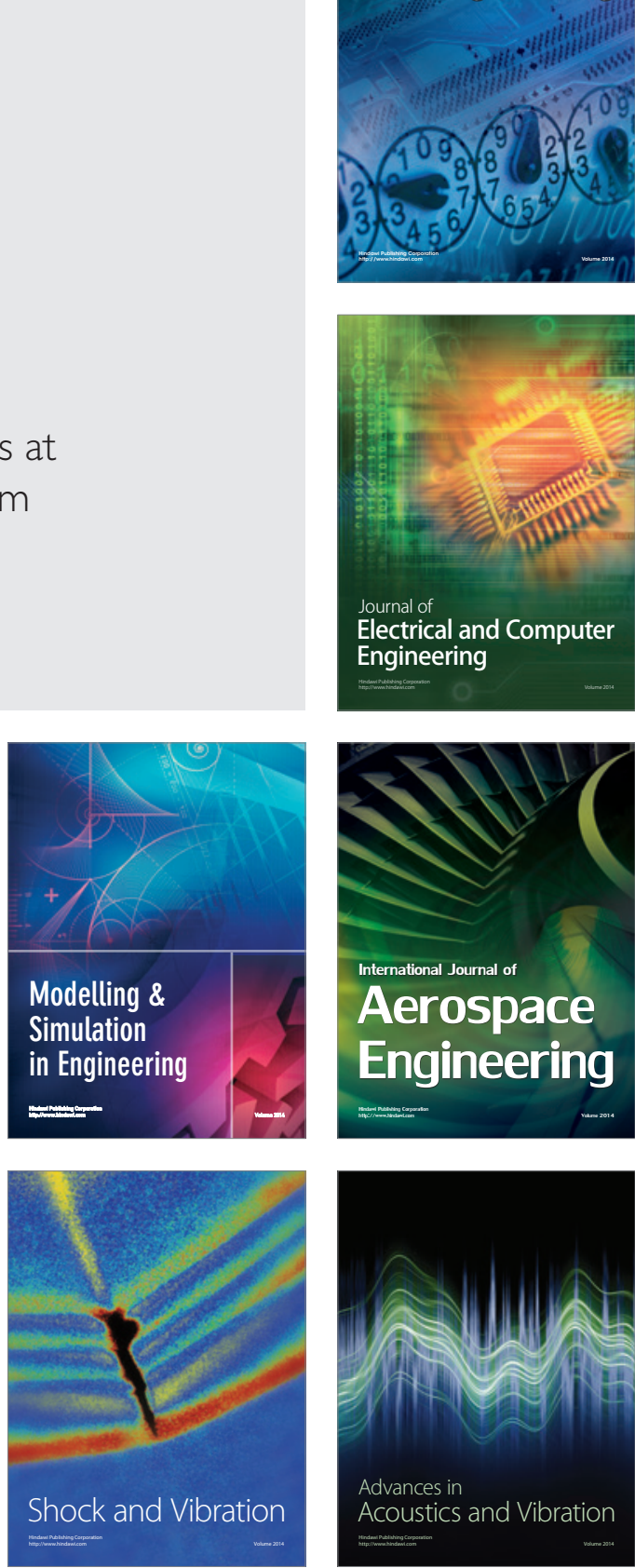